Amor Teresa Gutiérrez Sánchez El 10 de Mayo "Día de la Madre" en México o de Cómo Imponer un Modelo de Maternidad Revista Xihmai XII (23), 45-60, Enero - junio 2017

\title{
Xihmai
}

Universidad La Salle Pachuca

xihmai@lasallep.edu.mx

Teléfono: 01(771) 7170213 ext. 1406

Fax: 01(771) 7170309

ISSN (versión impresa):1870_6703

México

Amor Teresa Gutiérrez Sánchez

El 10 DE MAYO “DíA DE LA MADRE” en MÉXICO ODE CÓMO IMPONER UN MODELO DEMATERNIDAD

MAY 10 "MOTHER'S DAY" IN MEXICO OR HOW TO IMPOSE A MATERNITY MODEL

Xihmai, año 2017/vol. XII, número 23

Universidad La Salle Pachuca

pp. $45-60$ 
Amor Teresa Gutiérrez Sánchez El 10 de Mayo "Día de la Madre" en México o de

Cómo Imponer un Modelo de Maternidad

Revista Xihmai XII (23), 45-60, Enero - junio 2017

Xihmai 46 
Amor Teresa Gutiérrez Sánchez

El 10 de Mayo "Día de la Madre" en México o de

Cómo Imponer un Modelo de Maternidad

Revista Xihmai XII (23), 45-60, Enero - junio 2017

\section{El 10 DE MAYo “Día DE LA MADRE” en MÉXICO O DE CÓMO IMPONER UN MODELO DEMATERNIDAD}

MAY 10 "MOTHER'S DAY" IN MEXICO OR HOW TO IMPOSE A MATERNITY MODEL

Amor Teresa Gutiérrez Sánchez

Candidata a Doctora en Pedagogía. Facultad de Filosofía y Letras, UNAM. amortegusa@ hotmail.com

Recibido 06-12-16 Aceptado 19-12-16 Corregido 29-12-16

\section{Resumen}

Con base a la investigación de archivo de Martha Acevedo sobre el 10 de mayo (Día de la Madre) en México y gracias a los aportes teóricos de las historiadoras feministas sobre la maternidad, se reflexiona sobre el festejo a un modelo único de maternidad, cuyos inicios se remontan a la segunda década del Siglo XX en medio de disputas políticas. El análisis crítico de este episodio de la historia mexicana permite comprobar cómo el cuerpo de las mujeres y las decisiones sobre su sexualidad continúan siendo mediadas por el embate cultural del "Día de la Madre" (enero, 2016).

Palabras clave: maternidad, feminismo, 10 de mayo, Día de la Madre, Martha Acevedo

Based on Martha Acevedo's archival research about 10 de mayo (mother's day) in Mexico and thanks to the theoretical contributions of feminist historians on motherhood, we reflect on the celebration of a unique model of maternity, whose beginnings go back to the second Decade of S. XX in the middle of political disputes. The critical analysis of this episode of Mexican history shows how women's bodies and decisions about their sexuality continue to be mediated by the cultural "mother's day" (January, 2016)

Key words: motherhood, feminism, 10 de mayo, mother's day, Martha Acevedo 
Amor Teresa Gutiérrez Sánchez

El 10 de Mayo "Día de la Madre" en México o de

Cómo Imponer un Modelo de Maternidad

Revista Xihmai XII (23), 45-60, Enero - junio 2017

\section{Introducción}

La maternidad es un tema que ha fungido como objeto de estudio para intelectuales, académicas y activistas en el transcurso del feminismo como movimiento social, pensamiento crítico y posición política.

De manera particular, los estudios históricos han contribuido a situar la maternidad como un hecho social, histórico y contextual, razón por la cual, el análisis sobre el tema en México no puede sustraerse a la investigación sobre los orígenes del festejo del 10 de mayo "Día de la Madre". Para tal empresa, el libro de Martha Acevedo, El diez de mayo (1982), resulta fundamental por ser la primera investigación al respecto.

La presente propuesta representa un primer paso en el análisis correlativo entre el trabajo de Acevedo y diversos argumentos críticos que han contribuido a mostrar que la maternidad es, parafraseando a Mónica Bolufer (2010), un fenómeno de distintas dimensiones, que a la vez es investido por los significados culturales de la sociedad y el periodo histórico al que se adscriba su análisis.

\section{Madre y maternidad desde la crítica feminista: aproximaciones y aportes}

Desde el siglo pasado, el trabajo intelectual, académico y militante de las feministas de la segunda y tercera ola ha producido un importante corpus teórico sobre el tema, de manera que hoy en día, encontramos análisis sobre el complejo devenir de los términos madre y maternidad, reflexiones sobre las principales figuras de representación de la madre e incluso sobre las particulares expresiones disidentes del ideal de maternidad occidental, entre otros planteamientos.

La propuesta crítica resultante conforma un espectro polifónico que permite trazar nuevos caminos por los cuales transitar para el estudio de las diversas posibilidades de ser madre y de pensar la maternidad, así como de proponer lugares de enunciación, observación y producción de conocimiento.

Xihmai 48 
Amor Teresa Gutiérrez Sánchez

El 10 de Mayo "Día de la Madre" en México o de

Cómo Imponer un Modelo de Maternidad

Revista Xihmai XII (23), 45-60, Enero - junio 2017

En este sentido, se retoman algunas reflexiones que sirven como punto de partida para la argumentación que aquí se presenta sobre el establecimiento en México de una fecha destinada a festejar a "la madre"1.

En primer lugar, habremos de remontarnos a los estudios hechos por las historiadoras feministas, quienes han dedicado sus esfuerzos a investigar el origen de los términos madre y maternidad en occidente desde la antigüedad clásica hasta la modernidad, evidenciando por una parte, que la maternidad es un hecho histórico y contextual y por otra, contribuyendo a desnaturalizarla al plantearla como un hecho social factible de ser analizado.

Tal es el caso del estudio histórico de la filósofa Elizabeth Badinter, ¿Existe el instinto maternal? Historia del amor maternal. Siglos XVII al XX (1991), libro en el que enfatiza que el amor maternal, tal como se entiende en la actualidad, es heredero de una serie de convulsiones de índole político impulsado en las principales potencias europeas, cuyo efecto ideológico, no obstante, ha alcanzado latitudes lejanas.

Otro ejemplo importante es el texto histórico de Yvonne Knibiehler, Historia de las madres y de la maternidad en Occidente (2000), trabajo que, entre otras cosas, centra su análisis en temas como en control natal de los estados nacionales durante la posguerra, así como los discursos de índole moral y religioso que, posterior a la revolución francesa, se difundieron en tratados filosóficos como El Emilio (Rousseau traducido en 1970).

Estos estudios han tenido eco en diversas investigaciones y análisis posteriores, al grado de identificar las vetas que se abren en relación al estudio de la maternidad.

Por su parte, Silvia Tubert, psicoanalista feminista, editora de Figuras de la madre (1996), libro que se ha forjado como un clásico en la literatura sobre la maternidad, refiere que la tradición crítica feminista ha generado tres principales vertientes en sus aproximaciones al análisis de la maternidad.

\footnotetext{
${ }^{1}$ En esta primera parte del texto se apreciará que cuando se escriba "la madre", madre o maternidad, se hará empleando gestos ortográficos como las comillas o el resaltado en cursivas. Esto obedece a la argumentación que se apreciará a lo largo del texto y que parte de no asumir que madre y la maternidad son conceptos con un único significado.
}

Xihmai 49 
Amor Teresa Gutiérrez Sánchez

El 10 de Mayo "Día de la Madre" en México o de

Cómo Imponer un Modelo de Maternidad

Revista Xihmai XII (23), 45-60, Enero - junio 2017

Con tan complejos y variados análisis como antecedentes que ponen en cuestión la maternidad como un hecho únicamente natural, resulta como mínimo problemático plantear la idea de pensar que existe solo una forma de ser madre. A cambio, lo que encontramos son discursos encaminados a cosificar a "la madre", es decir, crear un estereotipo ficcional fundado en una evidencia corporal: la capacidad reproductiva de las mujeres.

Es por eso que la presente propuesta, retoma el interés de Tubert (Ibid. p.7) de "analizar la construcción de las representaciones [de la maternidad]" y el proceso por el que ellas mismas configuran la realidad, es decir, rastrear cómo hoy en día, en México se ha llegado el extremo de celebrar a la madre, o si se quiere, incluso, "a las madres" sin que medie en este festejo un mínimo interés por preguntarnos sobre lo que significa para esta sociedad sostener una especie de culto a la maternidad.

En México también se ha pensado y escrito mucho sobre el tema de la mano de la crítica feminista. Los estudios al respecto provienen de feministas de diversas disciplinas como la antropología, la historia, la sociología, el derecho, la economía política, el arte, entre otras.

Han visto la luz investigaciones sobre la conducta sexual y reproductiva de las mujeres desde un punto de vista sociológico (Sánchez, 2003), se ha escrito sobre el aborto, respecto a las pautas sociales persistentes en poblaciones bien identificadas (Eriviti, 2001), análisis que van del ámbito rural (Fagetti,1995) a las grandes ciudades y se ha debatido sobre su criminalización y su despenalización (Valdés, 2001; Lamas, 1994).

Por otra parte, han proliferado los análisis sobre las variaciones relativas a la fecundidad (Figueroa, 1989; González, 1993) han surgido estudios sobre el fenómeno social referente a la persistencia de madres solteras (González, 1997), así como se ha estudiado la maternidad en intersección con el trabajo remunerado.

Esta múltiple derivación de temas para el análisis es significativa porque evidencia la necesidad de pensar detenidamente la maternidad y analizar los fenómenos relacionados con el tema.

Marta Lamas, por su parte, se ha ocupado del mito de la "madrecita santa" a través del análisis de la relación entre las virtudes de la Virgen de Guadalupe

Xihmai 50 
Amor Teresa Gutiérrez Sánchez

El 10 de Mayo "Día de la Madre" en México o de

Cómo Imponer un Modelo de Maternidad

Revista Xihmai XII (23), 45-60, Enero - junio 2017

y las virtudes atribuidas a la madre mexicana: "el mito de la madre es el mito de la omnipotencia materna surgida del amor incondicional, de la abnegación absoluta y del sacrificio" (1995, p. 174).

\section{El 10 de mayo en México: "el Día de la Madre"}

En este apartado nos interesa abordar la creación del festejo del 10 de mayo "Día de la Madre" en México al trenzar en su argumentación algunas reflexiones que por una parte, se han suscitado a partir de la investigación de Martha Acevedo al respecto, tal como el mito de la "madrecita santa" que desarrolla Marta Lamas, así como aportes analíticos provenientes de teóricas feministas como Mónica Bolufer (2010), catedrática de la Universidad de Valencia y especialista en historia de las mujeres en la Modernidad, quien nos recuerda que historizar la maternidad pone de manifiesto que no ha existido un modelo único que represente a todas las madres.

A lo largo del siglo XX se ha forjado en el imaginario social mexicano una fecha que es motivo de festejo: el 10 de mayo "Día de la Madre"; no obstante, poco se conoce sobre sus orígenes y menos aún sobre los personajes e instituciones involucradas en la creación de esa fecha que desde 1922 se celebra en todo el territorio mexicano.

Martha Acevedo, autora de Nuestro sueño está en escarpado lugar $(1970)^{2}$, a inicios de la década de los ochenta y gracias a la invitación de la entonces directora del Archivo General de la Nación, Alejandra Moreno Toscano, decidió analizar imágenes ahí resguardadas, relacionadas con un tema que atravesaba varios periodos presidenciales y que además, involucraba a personalidades del ámbito político, cultural y religioso de este país en la segunda década del siglo pasado: el festejo del 10 de mayo.

Su trabajo de archivo dio como resultado el libro titulado El diez de mayo (1982), en el que explica que la iniciativa de dedicar un día de festejo a la madre mexicana provino del entonces director del periódico Excélsior, Rafael Alducin, quien invitó a sumarse a su campaña a personajes importantes del ámbito político y religioso, entre los que destacan el entonces secretario de

${ }^{2}$ Crónica a la que se le adjudica el inicio organizativo de la llamada segunda ola del feminismo en México. 
Amor Teresa Gutiérrez Sánchez

El 10 de Mayo "Día de la Madre" en México o de

Cómo Imponer un Modelo de Maternidad

Revista Xihmai XII (23), 45-60, Enero - junio 2017

Educación Pública, José Vasconcelos y el entonces arzobispo primado de México.

Con sendos antecedentes sobre el Día de la Madre, resulta pertinente continuar reflexionando sobre la relación entre esta fecha y la historia de México, tal como lo manifiesta Acevedo al inicio de su libro: ¿Qué tiene que ver esta fecha, un tanto banal, con la historia de México? (Ibíd., p. 7).

Desde la perspectiva crítica feminista sabemos, como Acevedo lo sabía, que tiene mucho que ver, y que incluso es determinante para los intereses nacionalistas de un estado moderno, impulsar un discurso sobre la familia tradicional en el que los roles de cada integrante queden bien establecidos, especialmente el correspondiente al personaje de la madre.

Entre la familia, la madre tendría un papel preponderante no solo como reproductora de su progenie, es decir, como la encargada de cumplir el mandato social (Tubert, Ibíd.) de ser madre, sino también como la encargada de educar a los suyos entregándose a su cuidado de manera incondicional, reproduciendo con ello los valores morales bien establecidos.

Lisette Rivera (2009, p. 61), en su análisis sobre la prensa de línea católica de principios del siglo XX, analiza cómo la mujer en su rol de esposa y madre tenía un papel importante de acuerdo "(...) a los afanes de progreso, civilización y consolidación del Estado nacional", de manera que los periódicos hacían eco de ello al difundir noticias y recomendaciones sobre aspectos tales como la lactancia, la crianza y educación de los hijos, los atributos de la "buena madre", entre otros.

De regreso a la creación del 10 de mayo, es importante resaltar que la idea de festejar a la madre mexicana, no provenía solo de la influencia del festejo que ya se hacía en Estados Unidos de Norteamérica, sino que meses antes de ser publicada tal iniciativa, existía una polémica que el mismo Excélsior promovió al denunciar que en el estado de Mérida se habían repartido unos folletos que promovían la anticoncepción.

El título de los folletos era La limitación de la familia o la brújula del hogar (Acevedo, Ibíd.) y la autoría del contenido de los cuadernillos correspondía a

Xihmai 52 
Amor Teresa Gutiérrez Sánchez

El 10 de Mayo "Día de la Madre" en México o de

Cómo Imponer un Modelo de Maternidad

Revista Xihmai XII (23), 45-60, Enero - junio 2017

Margaret Sanger ${ }^{3}$, una enfermera estadounidense que se dedicaba a informar a las mujeres sobre el uso de métodos anticonceptivos, y quien por dicha causa fue aprehendida en varias ocasiones al grado de tener que salir de su país por un tiempo para evitar ser encarcelada nuevamente.

Desde luego, esta información no era del conocimiento de Alducin, el director del Excélsior, lo importante para la redacción de su diario era que tenía no solo una noticia que lograba escandalizar a la sociedad mexicana, sino que ese acto sería respondido con una campaña más que publicitaria política, por lo que el cuerpo de las mujeres otra vez era el campo de batalla para la fracción conservadora del país.

En Yucatán, en 1917 se realizó el primer congreso feminista de México y dicho evento fue convocado por el entonces gobernador Salvador Alvarado, simpatizante de la educación racionalista, por esta razón Acevedo refiere que la gente en Yucatán recibió de buen agrado la repartición de dichos folletos, pues venían organizándose en actividades colectivas impulsadas por gobiernos progresistas (De Dios y Navarro, 2004, p. 68). Para Acevedo (Ibíd.):

Y no es una coincidencia que, a principios del siglo XX, en Yucatán se diera un clima social que permitió que muchas mujeres participaran en los asuntos públicos y tuvieran manera de evitar la concepción. Esto fue posible gracias al trabajo de las ligas feministas que Salvador Alvarado impulsó y que Felipe Carrillo Puerto apoyó entre 1915 y 1924.

Efectivamente, Felipe Carrillo Puerto era el gobernador de Yucatán en los tiempos del reparto de los folletos anticonceptivos de Sanger, y según Acevedo, él mismo respaldaría dicha iniciativa. Por ello es que la autora atribuye a una disputa política el resultado de la campaña para festejar a la madre mexicana como respuesta reaccionaria a la mínima muestra de intención de que las mujeres tomaran las decisiones que solo a ellas compete en términos reproductivos.

Marta Lamas, en su análisis sobre el mito de la "madrecita santa" (1995) y siguiendo la investigación de Acevedo, invita a preguntarse ¿"qué está

${ }^{3}$ Margaret Sanger, fue a su vez, la organizadora del primer Congreso de Población realizado en Suiza en 1927y a fundadora de la primera Clínica de control natal en Brooklyn, Estado Unidos. 
Amor Teresa Gutiérrez Sánchez

El 10 de Mayo "Día de la Madre" en México o de

Cómo Imponer un Modelo de Maternidad

Revista Xihmai XII (23), 45-60, Enero - junio 2017

encubriendo la avalancha discursiva y comercial que exalta la maternidad"? (p. 173) Avalancha que se impuso con rigor en términos mediáticos y que los grandes empresarios aprovecharon para promover la compra sin recato de todo tipo de artículos para "agasajar a mamá", tal como lo hacen en la actualidad.

Acevedo da una pista de lo que hay detrás de este festejo con su investigación de archivo y con ello corre el telón de lo que parece una puesta en escena bien organizada, que precisamente en su repetición, es decir, en la necesidad de repetir cada año que hay un día dedicado a festejar a la madre, da cuenta del elemento ficcional que lo acompaña.

Ser madre o hacer de madre implica una inversión de tiempo, dinero y mucho trabajo; sin embargo, nada de lo anterior se ve reflejado en ningún momento dentro del discurso de festejo a la madre, a quien se procede a estereotipar como "la que nos amó antes de nacer", según versa en la placa que acompañó varias décadas al monumento a la madre de la calle Sullivan en la ciudad de México, el cual, por cierto, fue construido en 1949 gracias a la iniciativa del periódico Excélsior.

Por otra parte, en este trabajo destaca la participación de la Iglesia católica, no solo porque fue la institución religiosa que apoyó abiertamente la instauración de esta fecha como día de celebración, sino porque abiertamente es la que predica una moral basada en el ejemplo de "la virgen madre", de quien las mortales de carne y hueso habrán de copiar sus valores morales.

Recordemos que entre los atributos de la madre, es decir, de la "buena madre", están para la Iglesia, el "recato, contención, sumisión, piedad y devoción religiosa" (Rivera Ibíd., p. 62).

O bien, como afirma Marta Lamas:

Cuando se habla de la maternidad solo en términos de "destino sublime" se olvidan las horas/trabajo que implica; cuando se elogia la abnegación, se deja de lado el despotismo y la arbitrariedad que suele acompañar la crianza; cuando se alaba la devoción, se desconocen el maltrato y la crueldad. Por otro lado, las embarazadas no consiguen empleo, las parturientas son maltratadas en los hospitales y las madres no cuentan con opciones de cuidado para los hijos, lo que las limita laboral, política y socialmente, además de cargarlas con el desgaste físico y emocional que supone atender a los hijos (Ibíd., p. 176).

Como vemos, uno de los peligros de asumir que la maternidad es una condición inherente al género femenino, es el hecho de limitarnos al análisis complejo Xihmai 54 
Amor Teresa Gutiérrez Sánchez

El 10 de Mayo "Día de la Madre" en México o de

Cómo Imponer un Modelo de Maternidad

Revista Xihmai XII (23), 45-60, Enero - junio 2017

del tema, que como hemos dicho, es, entre otras cosas, un hecho social, histórico y contextual.

Evitamos también observar las conformaciones familiares que no suscriben al modelo familiar tradicional, entre ellos las familias de madres lesbianas o madres solteras, madres que se autodenominan madres a contra corriente ${ }^{4} \mathrm{o}$ bien, a las madres subversivas, es decir, madres que subvierten el orden establecido para las mujeres: el mandato social de la maternidad.

Cabe destacar que estas conformaciones familiares son conscientes de lo que representa subvertir el orden heterosexual establecido en términos filiales, no obstante continúan adelante con su interés de traer al mundo y de educar a seres libres o bien, seres que respeten, entre otras cosas, la diversidad de opiniones respecto de la sexualidad.

Como afirma María Llopis, artista feminista del Estado español, y autora del libro Maternidades subversivas (2015):

La maternidad es mucho más que maternidad biológica. Hay un montón de personas viviendo la maternidad de forma plural, más allá de las limitaciones de la sexualidad coitocentrista. Más allá de cómo el patriarcado capitalista ignora los cuidados, que son la base de la supervivencia de la sociedad (p. 19).

De igual forma, las constituciones familiares hoy en día se reconocen como variables y complejas, así lo manifiestan las coordinadoras del libro Familias en el siglo XXI: realidades diversas y políticas públicas (Melgar y Lerner, 2010, p. 13):

Frente a las miradas fundamentalistas o esencialistas que plantean un ideal de familia en singular, inmutable, ahistórico, y que no reconocen la diversidad de formas de estructura, dinámica y organización familiar, el seminario dio cabida a una pluralidad de voces, percepciones y perspectivas que dan cuenta tanto de esa diversidad como del entrelazamiento y multiplicidad de un cúmulo de factores sociales, económicos, políticos, culturales y valorativos que están en permanente transformación y que se ponen en juego e inciden en los espacios y las configuraciones familiares .

\footnotetext{
${ }^{4}$ En mayo de 2015 un grupo de mujeres se organizó en la Ciudad de México, quienes se nombraron a sí mismas: madres a contracorriente, y realizaron un conversatorio donde exponen sus puntos de vista críticos sobre la maternidad entendida en los términos tradicionales asociados a la moral católica y al conservadurismo del Estado. El audio de la conversación está disponible en: https://goo.gl/Dmd1NX
} 
Amor Teresa Gutiérrez Sánchez

El 10 de Mayo "Día de la Madre" en México o de

Cómo Imponer un Modelo de Maternidad

Revista Xihmai XII (23), 45-60, Enero - junio 2017

Tras la revisión crítica feminista sobre la vida familiar, los asuntos "familiares" dejaron de ser vistos como pertenecientes al espacio doméstico para ser considerados como parte constitutiva y constituyente de la organización política de las sociedades en que se enmarcan. Otro aporte al pensamiento y a la humanidad.

Si bien no se agotaron, ni mucho menos, las vetas de análisis críticos que sobre el tema maternidad se podrían hacer, y mucho menos se agotó el análisis de los aportes que un libro relativamente pequeño en su extensión El diez de mayo, de manera potencial sí fue posible por lo menos trazar algunos datos relacionados con la instauración de esa fecha como la representante de un modelo de hegemónico de maternidad que por una parte vemos reproducir año con año a través de festivales escolares y campañas comerciales intentando vender un variado número de productos "diseñados para la ocasión".

Por otra parte, la posibilidad de analizar de manera crítica el hecho de que un país como México dedique un día para festejar a un tipo de madre, a la "buena madre", inevitablemente produce interrogantes sobre lo que bien podría ser la otra cara de la moneda de la celebración: el castigo.

Margaret Sanger no ha sido la única activista encarcelada por difundir los métodos de anticoncepción entre las mujeres, en México en pleno siglo XXI se continúa criminalizando a las mujeres que abortan en los diferentes estados de la República, a excepción de la ciudad de México, gracias a que en 2007 fue aprobada la Interrupción Legal del Embarazo (ILE).

Por ello resulta importantísimo indagar en la historia de México de principios del siglo XX, para identificar los procesos, los actores, los medios y las coyunturas políticas y sociales que hablan abiertamente sobre la maternidad, para conocer qué uso le dan.

Me permito concluir con una última reflexión de Martha Acevedo (Ibíd. P. 70): Un vistazo a la historia nos permite reconocer cómo los escándalos en torno a los métodos anticonceptivos que se produjeron a principios del siglo XX han sido sustituidos actualmente, a principios del siglo XXI, por el escándalo en torno a la interrupción legal del embarazo. Y parecería que la dificultad radica en ver a las mujeres como sujetos en su propio derecho

Xihmai 56 
Amor Teresa Gutiérrez Sánchez

El 10 de Mayo "Día de la Madre" en México o de

Cómo Imponer un Modelo de Maternidad

Revista Xihmai XII (23), 45-60, Enero - junio 2017

¿Cómo ve el gobierno actual a las mujeres? ¿Cómo han sido vistas las mujeres a lo largo de la historia de la humanidad? ¿Qué significa para cada habitante de México el Día de la Madre? ¿Qué tanto conocemos sobre la historia de una de las fechas más significativas para la sociedad mexicana? ¿Qué postura tomamos al respecto?

\section{Conclusiones}

La revisión crítica de la maternidad no necesariamente implica una posición contraria a la posibilidad de ser madre: en este trabajo no se está en contra de las madres. Nuestro interés es poner en cuestión el tema para evidenciar los usos históricos que se ha hecho del término maternidad en las diferentes sociedades, particularmente en el contexto mexicano posrevolucionario, para cuyo proyecto de nación era indispensable el control de la sexualidad de las mujeres, en aras de reproducir a "los hijos de la nación" moderna.

Por ello, sin dejar de reconocer la fuente de conocimiento y satisfacciones que puede proveer el hecho de ser madre para quien así se asume, nos interesa analizar la complejidad de quienes se asumen como madres, pero también los usos de la maternidad que se hace en las sociedades.

En otras palabras, esta propuesta asume que la maternidad es, en términos de experiencia, un proceso complejo que dista mucho de las representaciones románticas fundamentadas en un supuesto "instinto materno". Y que los discursos sobre la maternidad son múltiples y diversos; que bien pueden ir de la idea glorificada de la madre como imagen divina a situarla como la responsable de toda clase de infortunios.

\section{Fuentes de CONSUlta}

- ACEVEDO, M. (1970). Nuestro sueño está en escarpado lugar. Debate Feminista, México, año 6, vol. 12, octubre de 1995, pp. 360361.

(1982 [2012]). El diez de mayo. México: Ule Libros.

- BADINTER E. (1991). ¿Existe el instinto maternal? Historia del amor maternal. Siglos XVII al XX. Madrid: Paidós. 
Amor Teresa Gutiérrez Sánchez

El 10 de Mayo "Día de la Madre" en México o de

Cómo Imponer un Modelo de Maternidad

Revista Xihmai XII (23), 45-60, Enero - junio 2017

- $\quad$ BOLUFER, M. (2010). "Madres, maternidad: nuevas miradas desde la historiografía". En: Franco, G. (Ed.) Debates sobre la maternidad desde una perspectiva histórica (Siglos XVI al XX). (Pp. 51-81). Barcelona: Icaria.

- DE DIOS, D. y Navarro, M. (2004). "El feminismo como movimiento social" En: Chávez, J. (Coord.). Perspectiva de Género. (Pp. 23-56). México: UNAM/Plaza y Valdés.

- ERIVITI, J. (2001). Aborto y redes sociales en México. Significados, vivencias y apoyo social a mujeres. Barcelona: universidad de Barcelona. Tesis doctoral.

- $\quad$ FAGETTI, A. (1995). "Los cambiantes significados de la maternidad rural" En: González, S. y Salles, V. (Comps.). Relaciones de género y transformaciones agrarias. (Pp. 301-337). México: El Colegio de México.

- FIGUEROA, B. (1989) (Comp.). La fecundidad en México. Cambios y perspectivas. México: El Colegio de México.

- GONZÁLEZ, A. (1993). "La fecundidad no deseada en México". En: Estudios demográficos y urbanos, vol. 8, núm. 2 (mayo-abril). Pp. 287-306.

- $\quad$ GONZÁLEZ, S. (1997). "Novias pedidas, novias robadas, polígamos y madres solteras. Un estudio de caso en México rural 1930-1990". En: López, M. (Comp.). Hogares, familias, desigualdades, conflicto, redes solidarias y parentales. (Pp. 29-38). México/SOMEDE.

- $\quad$ KNIBIEHLER, I. (2000). Historia de las madres y de la maternidad en Occidente. Argentina: Ediciones Nueva Visión SAIC.

- LAMAS, M. (1994). "Maternidad: ¿qué proponer como feministas?" En: (Talamante, C., Salinas, f., Valenzuela, M.L. (coord.). Repensar y politizar la maternidad. Un reto de fin de milenio. (Pp. 37-50). México: Grupo de Educación Popular con Mujeres (GEM).

(1995). “¿Madrecita Santa?”. En Florescano, E. (Comp.) "Mitos mexicanos". (Pp. 173-178). México: Ed. Aguilar.

Xihmai 58 
Amor Teresa Gutiérrez Sánchez El 10 de Mayo "Día de la Madre" en México o de Cómo Imponer un Modelo de Maternidad Revista Xihmai XII (23), 45-60, Enero - junio 2017

- $\quad$ LERNER, S. y Melgar, L. (2010). (Coord.) Familias en el siglo XXI: realidades diversas y políticas públicas. México: UNAM, PUEG, COLMEX.

- $\quad$ LLOPIS, M. (2015). Maternidades subversivas. Bilbao: Txalaparta

- ROUSSEAU, J. (1762 [2009]). Emilio o de la Educación. México: Porrúa.

- RIVERA, L. (2009). "Discursos e imaginarios sobre la maternidad en México a través de la prensa católica de la ciudad de Morelia, 18701910”. En: Suárez, Carmen. (Ed.). Maternidades. (De)construcciones feministas. Oviedo: KRK Ediciones.

- SÁNCHEZ, A. (2003). Mujeres, maternidad y cambio. Prácticas reproductivas y experiencias maternas en la Ciudad de México. México: UAM/PUEG

- TUBERT, S. (1996). Figuras de la madre. Madrid: Cátedra/Universidad de Valencia/Instituto de la Mujer.

- VALDÉS, M. (2001). Controversias sobre el aborto. México: UNAM. 
Amor Teresa Gutiérrez Sánchez El 10 de Mayo "Día de la Madre" en México o de

Cómo Imponer un Modelo de Maternidad

Revista Xihmai XII (23), 45-60, Enero - junio 2017

Xihmai 60 